\section{Haploinsufficiency of the melanocortin-4 receptor: part of a thrifty genotype?}

Roger D. Cone

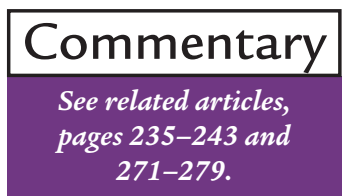

Vollum Institute, Oregon Health Sciences University, 3181 SW Sam Jackson Park Road, Portland, Oregon 97201, USA. Phone: (503) 494-4668; Fax: (503) 494-4534; E-mail: cone@ohsu.edu.

Allelic variation in certain "thrifty" genes is proposed to contribute to human obesity by altering the efficiency of energy storage in adipocytes without compromising survival or reproductive efficiency. The nature of these genes has been uncertain, but family studies and clinical analyses in two reports in this issue of the JCI $(1,2)$ show that mutations in $M C 4 R$, encoding the melanocortin-4 receptor, may be responsible for more than $4 \%$ of severe obesity in some populations. Family studies and careful clinical analyses argue that $M C 4 R$ has the properties of a gene that could contribute to a thrifty phenotype.

Clinical studies as well as personal experience show that there is variability in the efficiency with which humans store calories in the form of fat. Extreme examples are found in the remarkable plights of the Pima people of central Arizona and the Nauru Islanders of the West Pacific. These two ethnic groups suffer from a polygenic syndrome of obesity and diabetes with an incidence as high as $50 \%$ in the context of access to high-fat Western diets and a tremendous reduction in physical activity. Studies of these groups led to the theory of the "thrifty genotype" - the notion that living on the edge of survival for a sufficiently long period had fixed in the gene pool a collection of alleles that promote storage of fat in times of plenty (3). To be maintained in the gene pool, such alleles would have to promote survival in times of famine to a greater extent than they might compromise health and reproductive efficiency, even if, as proposed originally, they were to promote diabetes directly.

\section{Characterization of leptin}

The identification of the hormone leptin as a regulator of metabolic level and feeding behavior validated the notion of an adipostat that responds to changing energy stores, and it further suggested that single genes could alter the set point of adipose stores (4). However, the apparent role of leptin as a gatekeeper of reproductive competence (5) and the resulting infertility in leptin-deficient mice (and, presumably, humans with defective leptin signaling) argue that $O B$ or any other genes acting broadly on the leptin axis would not be candidate thrifty genes. $M C 4 R$, conversely, acts as an obesity gene without being required for reproduction.

than exclusively in the skin $(6,7)$. The agouti protein acts as a competitive antagonist, not only of the MC1-R, the melanocyte-stimulating hormone receptor, but also of the MC4-R (8). With the demonstration that the MC4$\mathrm{R}$ is expressed in hypothalamic nuclei involved in the regulation of energy homeostasis (9), this finding led to the hypothesis that the agouti obesity syndrome results from chronic blockade of hypothalamic MC4-R signaling. This hypothesis is now largely accepted, based on the demonstration that a cyclic peptide antagonist of the MC4-R stimulates food intake and energy storage (10), and that deletion of the mouse MC4R gene recapitulates the agouti obesity syndrome, including the unique neuroendocrine phenotype of increased linear growth (11). These data argue that the central melanocortin circuitry tonically inhibits energy

Characterization of the melanocortin system

The agouti gene was first shown to be responsible for one of the five monogenic obesity syndromes characterized in the mouse. The agouti obesity syndrome in the mouse resembles common human obesity much more than syndromes that result from leptin- or leptin receptor-deficiency. Agouti mice are obese but fertile, and they exhibit few associated endocrine abnormalities, outside of the hyperinsulinemia and incompletely penetrant diabetes normally associated with that degree of adiposity. Somatic growth of agouti mice is unusually rapid, a feature shared with humans with early-onset obesity. The dominant allele of agouti from the obese $A^{Y}$ agouti mouse results from a gene rearrangement, fusing the Raly promoter to the agouti coding sequences to produce a chimeric gene that expresses the agouti mRNA ubiquitously, rather storage. The curious finding that heterozygous MC4R knock-out mice develop an adipose mass intermediate to that of wild-type and homozygous knockouts suggests further that the circuit acts as a rheostat to regulate energy storage.

The high-affinity binding of agouti to the MC4-R was neatly explained by the discovery of an agouti homologue, agouti-related protein (AGRP), which is expressed in the neuropeptide Y-expressing neurons of the hypothalamus that regulate satiety. That AGRP occurs in nerve terminals in most of the same sites where hypothalamic proopiomelanocortin (POMC) terminals are found adds a further degree of regulatory complexity to the system $(12,13)$. AGRP mRNA and protein levels are dramatically upregulated by fasting or the absence of leptin, and this upregulation is blocked by leptin administration $(14,15)$. The AGRP 
protein has been demonstrated to function as a competitive antagonist of the central MC4-R and MC3-R receptors (16)

Evidence that melanocortin obesity syndrome could occur in humans came from the astute recognition of an agouti mouse-like syndrome in two families, resulting from null mutations in the POMC gene (17). These patients have a rare syndrome that includes adrenocorticotropic hormone (ACTH) insufficiency, red hair, and obesity, presumably resulting from a lack of ACTH peptide in the serum, a lack of $\alpha$ melanocyte-stimulating hormone $(\alpha-\mathrm{MSH})$ in the skin, and a lack of $\alpha-\mathrm{MSH}$ in the brain, respectively. These data demonstrated, for the first time, that the central melanocortin circuitry subserves energy homeostasis in humans as it does in the mouse. Shortly thereafter, the two laboratories reporting in this issue of the JCI published the first reports of heterozygous mutations in $M C 4 R$, associated with nonsyndromic obesity in two separate families $(18,19)$. These independent frameshift mutations were associated with obesity across two to four generations, but the data sets were too small to generate either significant LOD scores or meaningful physiological data. The two reports from the O'Rahilly and Froguel laboratories in this issue (1, 2 ), as well as recent additional reports (20-22), provide a clearer picture of the frequency and diversity of $M C 4 R$ mutations (Table 1); a better understanding of the genetics of the association of MC4R mutations with obesity and potential mechanisms; the first detailed clinical phenotype, to our knowledge; and the first report, to our knowledge, of individuals with homozygous mutant alleles (1).

\section{Analysis of MCR4 defects from human families}

Froguel and colleagues (2) have found eight new receptor mutations in a population of 209 probands randomly selected from a large cohort of morbidly obese

Table 1

Allelic variants of the human MC4-R

\begin{tabular}{|c|c|c|c|}
\hline Receptor variant & $\begin{array}{l}\text { Pharmacology } \\
\left(\mathrm{EC}_{50} / \mathrm{Kd} \text {; values are }\right. \\
\text { relative to wild-type })\end{array}$ & $\begin{array}{c}\text { Allele frequency } \\
\text { (obese/lean) }\end{array}$ & Reference \\
\hline СТCT $\Delta$, nt633 & null & $\begin{array}{c}0.008 \\
0.003 / 0\end{array}$ & $\begin{array}{l}(19) \\
(21)\end{array}$ \\
\hline GATT insertion, nt732 & null & 0.012 & $(18)$ \\
\hline \multirow[t]{2}{*}{ Val103Ile } & & $\begin{array}{l}0.021 / 0.023 \\
0.013 / 0.051\end{array}$ & $\begin{array}{l}(27) \\
(21)\end{array}$ \\
\hline & wild-type & $\begin{array}{l}0.017 / 0.021 \\
0.019 / 0.015 \\
0.006 / 0.009\end{array}$ & $\begin{array}{l}(20) \\
(2) \\
(1)\end{array}$ \\
\hline Stop codon, Tyr35 & null & $0.007 / 0$ & $(21)$ \\
\hline Ser30Phe & & $0.003 / 0$ & $(21)$ \\
\hline Asp37Val & & $0.007 / 0$ & $(21)$ \\
\hline Pro78Leu & & $0.003 / 0$ & (21) \\
\hline \multirow[t]{3}{*}{ Thr112Met } & & $0.007 / 0$ & (21) \\
\hline & wild-type & $0 / 0.011$ & (20) \\
\hline & & $0.002 / 0$ & $(1)^{\prime}$ \\
\hline Arg165Trp & & $0.003 / 0$ & (21) \\
\hline Gly252Ser & & $0.003 / 0$ & (21) \\
\hline Ile317Thr & & $0.003 / 0$ & (21) \\
\hline \multirow[t]{3}{*}{ Ile251Leu } & & $0.013 / 0$ & (21) \\
\hline & wild-type & $0.007 / 0.004$ & $(2)$ \\
\hline & & $0.024 / 0.028$ & (1) \\
\hline Silent change, C579T & wild-type & 0.013 & (21) \\
\hline Ile137Thr & $14.8 / 7.5$ & $0.003 / 0$ & (20) \\
\hline C593T, silent & wild-type & $0.002 / 0.004$ & $(2)$ \\
\hline 47-48insG & null & $0.002 / 0$ & (2) \\
\hline Thr11Ser & $1 / 1$ partially active & $0.002 / 0$ & (2) \\
\hline Arg18Cys & $1 / 1$ partially active & $0.002 / 0$ & (2) \\
\hline Thr150lle & $11.1 / 2.5$ & $0.002 / 0$ & (2) \\
\hline Ile170Val & 29/ partially active & $0.002 / 0$ & (2) \\
\hline Arg165Trp & 19.9/ partially active & $0.002 / 0$ & (2) \\
\hline Leu250Gln & constitutively active/ 0.11 & $0.002 / 0$ & (2) \\
\hline Ile301Thr & 4.4/ partially active & $0.002 / 0$ & (2) \\
\hline codon279insGT & null & $0.002 / 0$ & (1) \\
\hline C deletion, 28 bp $3^{\prime}$ of stop & & $0.002 / 0$ & (1) \\
\hline Asn62Ser & partially active & $0.002 / 0$ & (1) \\
\hline Arg165Gln & & $0.002 / 0$ & (1) \\
\hline Val253lle & & $0.002 / 0$ & (1) \\
\hline Cys271Tyr & no activity & $0.002 / 0$ & (1) \\
\hline
\end{tabular}

French patients (Table 1). Of the seven missense mutations, five are demonstrated by transfection into heterologous cells to have altered affinity for binding to $\alpha$-MSH or altered efficacy of activation by ligand (partial activity). One mutation, L250Q, is constitutively active and exhibits increased affinity for ligand. Mutations segregated with obesity in three of four families studied, but age at onset and severity of obesity were variable. In one family, the disease allele was a frameshift mutation occurring after codon 12. Although this allele seems certain to produce no functional protein, the family had no history of obesity outside of the proband, demonstrating that the penetrance of the mutation is incomplete: haploinsufficiency does not always lead to obesity. This was strongly suggested by an additional study which failed to document obesity due to haploinsufficiency of the MC4R gene in 27 individuals with deletions of $18 \mathrm{q}$ (23).

Vaisse et al. (2) suggest that the finding of silent carriers in the family with the frameshift after codon 12 argues against MC4-R-associated obesity occurring due to haploinsufficiency. Rather, they favor a dominant-negative mechanism for causation. While this mechanism is theoretically possible, the haploinsufficiency model remains tenable. In general, $G$ protein-coupled receptors are thought to act as monomers, and $G$ proteins are found in vast excess of receptors in the cells, providing little opportunity for dominant-negative mechanisms. One pharmacological study of MC4-R fails to document any dominant-negative activity of the CTCT $\Delta$ nt633 mutant or the GATT insertion nt732 mutant (24). Finally, in the majority of families (eight of ten) studied to date with null alleles of $M C 4 R$ or missense mutations that alter MC4-R pharmacology, nearly all of the carriers of the mutation are obese. For example, in a previous family study, 18 of 19 individuals containing different null alleles from three unrelated families were obese (22). The identification of a constitutively active mutant also may be used as an argument against haploinsufficiency. However, in the case of the rhodopsin receptor, one mutant receptor found associated with retinitis pigmentosa that was constitutively active in heterologous cells (25) appeared constitutively desensitized in transgenic mice (26), implying that the mutation created a null allele in vivo. Particularly given the ability of haploinsufficiency to cause obesity in an 
inbred mouse (11), the most parsimonious interpretation of the data set at this time is that a partial reduction in MC4-R function resulting from haploinsufficiency can cause obesity with variable penetrance and expressivity.

In the paper from O'Rahilly's group (1), MC4R sequences were determined in 243 unrelated United Kingdom probands, selected based on their development of severe obesity before the age of 10 , and in 54 nonobese controls. This group identified a new insertion and a new deletion mutant, as well as five new obesity-associated missense mutations (Table 1). Two of these missense mutations were characterized for functional activity, using a cAMP response element-luciferase reporter assay; the C271Y mutant lacked detectable activity while a N62S mutant receptor appeared to retain some marginal functional activity in the assay. Remarkably, four heterozygous carriers of the N62S mutation were not obese, while all five homozygotes from this consanguineous family exhibited severe obesity. This appears to be the first reported case of recessive inheritance of an MC4R allele associated with obesity.

These two research groups $(1,2)$ provide the first detailed physiological characterization of the melanocortin obesity syndrome in humans. Both concur that heterozygous MC4R mutations cause a nonsyndromic obesity. The Froguel study finds no differences in eating behavior (as measured by the Three-Factor Eating Questionnaire), fasting insulin and triglycerides, diabetes, or glucose intolerance between obese individuals carrying the MCAR mutation and matched obese people with the normal allele (2). Both groups report normal thyroid and adrenal axes $(1,2)$. The French study (2) reports a trend toward a greater incidence of childhood obesity among carriers of the MC4R mutations. Remarkably, parents of the children in the United Kingdom study all reported excessive hunger and food-seeking behavior from the age of 6 to 8 months (1). Additionally, the common association of pediatric obesity with increased growth velocity was seen, as affected children were in the 91st-99th centiles for height, and increased bone mineral density was also observed in this group. The phenotypes that set young carriers of MC4R mutations apart from other obese infants and children may subside with age, however, since the French study found no distinc- tive feeding behavior phenotype and no difference in mean heights in their group of obese adults (2).

The data from these two papers leave little doubt that heterozygous mutations in $M C 4 R$ predispose carriers to nonsyndromic obesity, most likely as a result of haploinsufficiency. These findings are important for a host of reasons. The mutations may be very useful tools for understanding MC4-R function and the cellular and molecular basis of energy homeostasis. Furthermore, numerous pharmaceutical and biotechnology companies are attempting to develop drugs for the treatment of obesity that act via the MC4-R and related neural circuits downstream of leptin. These drugs may act quite differently in patients with MC4R mutations or other forms of obesity resulting from defective melanocortin signaling.

The variable penetrance and expressivity of obesity in heterozygous individuals argues that the MC4-R acts in concert with a number of other genes to regulate energy storage under presumed conditions of a sedentary lifestyle and high-fat diet. But are the apparently nondiabetogenic mutant MC4R alleles a component part of the thrifty genotype? The individual mutant alleles are not out of HardyWeinberg equilibrium (21), suggesting no selective pressure on retention of mutant alleles in two European populations. Analysis of MC4R alleles in populations such as the Pima and Nauruans will be necessary to determine whether specific alleles of this gene, perhaps in concert with genes that are more potently diabetogenic, are part of a genotype that helped these groups survive across evolutionary time. sive inheritance of morbid obesity associated with melanocortin 4 receptor deficiency. J. Clin. Invest. 106:271-279.

2. Vaisse, C., et al. 2000. Melanocortin-4 receptor mutations are a frequent and heterogenous cause of morbid obesity. J. Clin. Invest. 106:253-262.

3. Neel, J.V. 1962. Diabetes mellitus: a thrifty genotype rendered detrimental by progress. Am. J. Hum. Genet. 14:353-362.

4. Zhang, Y., et al. 1994. Positional cloning of the mouse obese gene and its human homologue. Nature. 372:425-432.

5. Chehab, F.F., Lim, M.E., and Lu, R. 1996. Correction of the sterility defect in homozygous obese female mice by treatment with the human recombinant leptin. Nat. Genet. 12:318-320.

6. Bultman, S.J., Michaud, E.J., and Woychik, R.P. 1992. Molecular characterization of the mouse agouti locus. Cell. 71:1195-1204.

7. Miller, M.W., et al. 1993. Cloning of the mouse agouti gene predicts a novel secreted protein ubiquitously expressed in mice carrying the lethal yellow $\left(A^{y}\right)$ mutation. Genes Dev. 7:454-467.

8. Lu, D., et al. 1994. Agouti protein is an antagonist of the melanocyte-stimulating hormone receptor. Nature. 371:799-802.

9. Mountjoy, K.G., Mortrud, M.T., Low, M.J., Simerly, R.B., and Cone, R.D. 1994. Localization of the melanocortin-4 receptor (MC4-R) in neuroendocrine and autonomic control circuits in the brain. Mol. Endocrinol. 8:1298-1308.

10. Fan, W., Boston, B.A., Kesterson, R.A., Hruby, V.J., and Cone, R.D. 1997. Role of melanocortinergic neurons in feeding and the agouti obesity syndrome. Nature. 385:165-168.

11. Huszar, D., et al. 1997. Targeted disruption of the melanocortin-4 receptor results in obesity in mice. Cell. 88:131-141.

12. Ollmann, M.M., et al. 1997. Antagonism of central melanocortin receptors in vitro and in vivo by agouti-related protein. Science. 278:135-137.

13. Graham, M., Shuttre, J.R., Sarmiento, U., Sarosi, I., and Stark, K.L. 1997. Overexpression of Agrt leads to obesity in transgenic mice. Nat. Genet. 17:273-274.

14. Mizuno, T.M., and Mobbs, C.V. 1999. Hypothalamic agouti-related messenger ribonucleic acid is inhibited by leptin and stimulated by fasting. Endocrinology. 140:814-817.

15. Mizuno, T.M., et al. 1999. Fasting regulates hypothalamic neuropeptide Y, agouti-related peptide, and proopiomelanocortin in diabetic mice independent of changes in leptin or insulin. Endocrinology. 140:4551-4557.

16. Fong, T.M., et al. 1997. ART (protein product of agouti-related transcript) as an antagonist of MC-3 and MC-4 receptors. Biochem. Biophys. Res Commun. 237:629-631.

17. Krude, H., et al. 1998. Severe early-onset obesity, adrenal insufficiency and red hair pigmentation caused by POMC mutations in humans. Nat. Genet. 19:155-157.

18. Vaisse, C., Clement, K., Guy-Grand, B., and Froguel, P. 1998. A frameshift mutation in human MC4R is associated with a dominant form of obesity. Nat. Genet. 20:113-114.

19. Yeo, G.S.H., et al. 1998. A frameshift mutation in MC4R associated with dominantly inherited human obesity. Nat. Genet. 20:111-112.

20. Gu, W., et al. 1999. Identification and functional analysis of novel human melanocortin-4 receptor variants. Diabetes. 48:635-639.

21. Hinney, A., et al. 1999. Several mutations in the melanocortin-4 receptor gene including a nonsense and a frameshift mutation associated with dominantly inherited obesity in humans. J. Clin. Endocrinol. Metab. 84:1483-1486.

22. Sina, M., et al. 1999. Phenotypes in three pedigrees with autosomal dominant obesity caused by haploinsufficiency mutations in the melanocortin-4 receptor gene. Am. J. Hum. Genet. 65:1501-1507.

23. Cody, J.D., et al. 1999. Haplosufficiency of the melancortin-4 receptor gene in individuals with deletions of 18q. Hum. Genet. 105:424-427.

24. Ho, G., and MacKenzie, R.G. 1999. Functional characterization of mutations in melanocortin4 receptor associated with human obesity. $J$. Biol. Chem. 274:35816-35822.

25. Robinson, P.R., Cohen, G.B., Zhukovsky, E.A. and Oprian, D.D. 1992. Constitutively active mutants of rhodopsin. Neuron. 9:719-725.

26. Li, T., Franson, W.K., Gordon, J.W., Berson, E.L., and Dryja, T.P. 1995. Constitutive activation of phototransduction by K296E opsin is not a cause of photoreceptor degeneration. Proc. Natl. Acad. Sci. USA. 92:3551-3555.

27. Gotoda, T., Scott, J., and Aitman, T.J. 1997. Molecular screening of the human melanocortin-4 receptor gene: identification of a missense variant showing no association with obesity, plasma glucose, or insulin. Diabetologia. 40:976-979. 